\title{
AHP BASED MODEL FOR BANK PERFORMANCE EVALUATION AND RATING
}

\author{
Tihomir Hunjak \\ Faculty of organization and informatics \\ University of Zagreb \\ Pavlinska 2, Varaždin - Croatia \\ thunjak@foi.hr \\ Drago Jakovčević \\ CONVEST BANKA \\ Hinka Wurtha 20, Zagreb - Croatia \\ drago.jakovcevic@,convest.tel.hr
}

Key words: bank performance evaluation, financial ratios, Analytic Hierarchy Process, Data Envelopment Analysis

\begin{abstract}
Summary: This paper presents a multicriteria model for the bank performance evaluation. The model is based on the AHP method (Analytical Hierarchy Process), and it enables the integration of the quantitative data (measured by selected financial ratios) and qualitative data by which the bank features and some internal and external environment factors are described. The financial ratios used in the model are selected in accordance with the established results of the research on their correlation with different levels of the bank's efficiency, measured by means of Data Envelopment Analysis method. In the qualitative analysis, such features of the bank are used, which are usually included in specific analyses of the qualitative rating of banks, as well as in SWOT analysis, which is also used in the analysis of the business potential of a bank. The result of the evaluation of the sample of the Croatian banks by this model is presented.
\end{abstract}

\section{Introduction}

There are various motives to support the efforts of searching for the best method of bank performance evaluation. Managing the financial system of a country requires the kind of methods which enable the financial institutions to recognise the management problems on time so that steps for the protection of citizens and the whole system can be undertaken, since the level of problems resulting from poor bank management threaten the whole financial system of the country. From an individual bank's point of view, the interest of the bank for its efficient operation finds it important to be able to compare with the competitive banks and identify the causes of its (in)efficiency. Bank performance evaluation is of great importance for individuals, due to their need to protect against banking with a risk-running bank or due to the speculative motives linked to the activities on the capital market.

Bank performance evaluation is traditionally based on the analysis of financial ratios. However, regardless of how many ratios are being used, a model that would fully satisfy the analysis of needs and bank operations' efficiency evaluation has not been developed yet. For this reason, the financial ratio analysis is complemented with different quality evaluations, with features such as management quality, equity structure, competitive position and others to be included into the final evaluation.

The model presented in this paper has in the first place been developed with the purpose to compare (rank) the Croatian banks. The experience in either the Croatian banks' performance evaluation or their rating is not very rich. Traditionally, in the specialist literature the banks are annually rated according to the value of their assets, while the more complex models, which would make their multi-criteria 
evaluation possible, are occasionally published as a product of non-financial institution experts. The paper (Babić, Belak and Tomić-Plazibat, 1999) rates the banks against the following six criteria based on their results in 1997: (1) equity capital, (2) capital/assets ratio, (3) profit/income ratio, (4) EVA (Economic Value Added), (5) organization efficiency, and (6) VAIC (Value Added Intellectual Capital). In order to determine the importance of the listed criteria this paper uses the AHP method (Saaty, 1980), whereas the bank rating list was produced using, the multi-criteria analysis method, called the PROMETHEE (Brans, Mareschal and Vincke, 1986). Unlike those methods that are commonly used in the Croatian banking industry, this methodology makes more comprehensive bank performance analysis possible. However, even at the time of the analysis results release, this model was recognized as having a number of drawbacks, since some highly positioned banks appeared to be deep in difficulties leading eventually to their closure. In order to determine the banking operations re-engineering needs level, the authors of the paper (Belak, Kolaković, 1998) rated the Croatian banks according to their efficiency, measured by the ratio of non-interest costs against the sum of net interest earnings and non-interest income.

This paper is organized into five sections. The following section contains a short overwiev of some of the methods which are significant for this paper. The model for the bank performance evaluation, presented in the paper, is related to these particular methods. It presents: a short description of CAMEL system (Brockett, Charnes, Cooper, Hwang and Sun 1997), used for bank supervision by the American government office, the Federal Deposit Corporation; a brief description of DEA method (Cooper, Seiford and Tone, 2000), with a commentary explaining why this method is not the most appropriate for the Croatian banks' performance evaluation; the basic version of AHP (Saaty, 1980) method outline. The description of this method stresses the features that make it particularly appropriate for evaluation of a relatively small number of banks based on a relatively large number of criteria. In section 3 we propose the AHP model for bank comparison. Comprising quantity and quality criteria, the model's hierarchical criterion structure is being transformed into a ratings model.

The model implementation possibility is demonstrated in section 4, using the corpus of the most prominent Croatian banks, whose assets exceed $90 \%$ of the total Croatian banking assets. Finally, the last section discusses the advantages and disadvantages of the described model.

\section{An outline of methods appropriate for bank performance evaluation}

\subsection{CAMEL rating}

The early seventies in the USA saw the development of the bank evaluation system aimed at early identification of problems in banks' operations, followed by the corrective measures which were within government jurisdiction. The system that lays down the bank rating foundations was developed by the government Federal Deposit Insurance Corporation (FDIC) (Brockett, Charnes, Cooper, Hwang and Sun 1997) and is known as CAMEL (Capital, Asset, Management, Liquidity). The essence of the system is for the bank rating to be done on the basis of five components reflecting the bank's performance: capital, assets, management, equity shares and liquidity. Although nearly all the components (apart from management) can be quantitatively measured, due to the existence of developed metrics, the CAMEL model assesses them on the scale $1-5$, in accordance with the expert assessment on the problem identification level. The individual ratings are subsequently synthesized into an integral ranking list. The integral ranking list formation procedure has not been formalised in the form of a ready made model capable of offering a single solution, but it is rather left to subjective assessment of competent authorities. This rating is then integrated with a number of other reports published by the aforementioned FDIC agency, the US Office of the Comptroller of the Currency, the Board of Governors of the Federal Reserve System and the Federal Financial Institutions Examination Council. Regretfully, the public cannot directly benefit from this system of bank operations supervision. Namely, the CAMEL's bank individual rating is confidential information known only to the assessor and the bank management, with the sole purpose of bank supervision. Following the achieved rating, the frequency of the bank operations auditing is then determined; the banks with CAMEL 3, 4 and 5 rating need to be audited on an annual basis while those with 1 or 2 rating need to be audited at least once in two years. This system is mentioned in this paper merely as an example showing how it is possible to transform normally precisely 
measurable bank performance data into quality-related, less precise information, subsequently integrated into a complete evaluation (rating list).

\subsection{Data Envelopment Analysis (DEA)}

Data Envelopment Analysis (DEA) is a method for measuring the relative efficiencies of a set of comparable units such as banks, bank branches, schools, hospitals and similar institutions whose common feature is the ability for their activities to be described as the conversion of certain inputs into various forms of output. The basic concept in efficiency measurement with such entities is the relation of their output and input ratios. The concept is formalized in the following linear programming model, introduced by Charnes, Cooper and Rhodes in their paper ( Charnes, Cooper and Rhodes, 1978):

$$
\begin{aligned}
& \operatorname{Max}_{0}=\sum_{j=1}^{n} w_{j} y_{j k 0} \\
& \text { such that } \\
& \sum_{j=1}^{m} v_{i} x_{i k 0}=1 \\
& \sum_{j=1}^{n} w_{j} y_{j k} \leq \sum_{j=1}^{m} v_{i} x_{i k} \quad k=1, \ldots, K . \\
& w, v \geq \varepsilon
\end{aligned}
$$

where $K$ is the number of the decision making units, $m$ is the number of inputs, and $n$ is the number of outputs. This model is called the primal DEA model. It allows the unit being measured to determine the set of optimal weights $w_{j}$ for outputs denoted by $y_{j}$ and $v_{i}$ for intputs denoted by $x_{i}$ so as to maximize its efficiency $h_{0}$. Along with it a dual model is used as well.

Although there are numerous examples of the application of the bank and their branches efficiency measurement by this method, in Croatia it is not being very widely used due to some subjective reasons (supplementary education of management is required in order for the whole potential of information obtainable through the use of this method to be utilized to the full extent) but also a number of objective reasons resulting from its main limitation; the main condition for the method to be used is the required number of entities to be compared must be at least three times that of the total number of inputs and outputs. Since it only makes sense for the similar entities to be compared (banks with the similar structure of activities and operating in similar environment), and bearing in mind the number of banks operating in Croatia as well as the possible number of similarity-based bank clusters, the direct benefit of this method implementation would be hard to achieve. It would be more realistic then to expect the successful application of this method in bank branches efficiency assessment. While with bank and bank branches efficiency assessment the book value of equipment, labour (measured in man/hour per annum), material costs (all costs except labour and capital) are taken as input, the total deposits, total loans and total guarantees can be taken as output. The end product of this method application is the separation of banks (branches) into the efficient ones (the level of their efficiency is 1) and the inefficient ones (whose efficiency is less than 1). The DEA analysis results are directly followed by the useful bank management information, such as: what needs to be done in order for an inefficient bank to increase its efficiency, or to what extent and with what expenses this goal is obtainable. A huge number of different mathematical model variations has been developed for the DEA analysis (Cooper, Seiford and Tone, 2000).

\subsection{Analytic Hierarchy Process (AHP)}

AHP (Saaty, 1980) is one of the well known and recently also one of the most widely exploited decision making methods in cases when the decision (the selection of given alternatives and their ranking) is based on several attributes used as criteria. Complex decision problem solving which uses this method is based on the problem decomposition into a hierarchy structure which consists of the elements such as: the goal, the criteria (sub-criteria) and the alternatives. The other significant AHP method component is 
the mathematical model by which the priorities (weights) of elements positioned on the same hierarchy structure level are calculated.

The method application can be explained in four steps:

(1) The hierarchy model of the decision problem is developed in such a way that the goal is positioned at the top, with criteria and sub-criteria on lower levels and finally alternatives at the bottom of the model. The figure 1 shows such a general model.

(2) On each hierarchy structure level the pairwise comparisons should be done by all possible pairs of the elements of this level. The decision maker's preferences are expressed by verbally described intensities and the corresponding numeric values on 1-3-5-7-9 scale (Saaty, 1980).

(3) On the basis of the pairwise comparisons relative significance (weights) of elements of the hierarchy structure (criteria, sub-criteria and alternatives) are calculated, which are eventually synthesised into an overall alternatives priority list.

(4) The sensitivity analysis is carried out.

The following figure illustrates step (1):

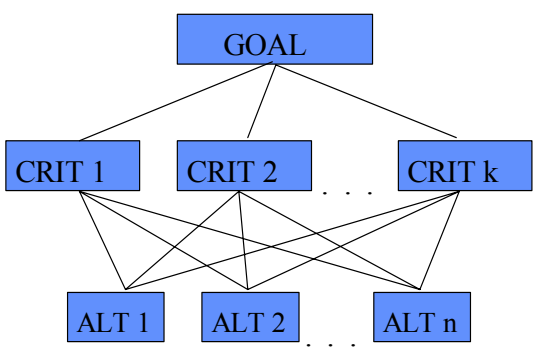

Figure 1: Basic AHP model with goal, criteria and alternatives.

In order to explain step 2 we will use the mathematical notation. Let us assume that $n$ is the number of criteria (or alternatives) whose weights (priorities) $w_{i}, i=1, \ldots, n$ we need to be determined on the basis of their value assessment ratios, which are denoted as $a_{i j}=w_{i} / w_{j}$. We suppose that $a_{i j}>0$ and $a_{i j}=a_{j i}{ }^{-1}$. If the relative significance ratios $a_{i j}$ are used to form the matrix $A$, and in the case of consistent evaluations where $a_{i j}=a_{i k} a_{k j}$ the equation $A w=n w$ is satisfied.

The matrix $A$ is characterised by special features (all its rows are proportional to the first row, the elements $a_{i j}$ of this matrix are all positive and $a_{i j}=a_{j i}{ }^{-1}$ is valid) due to which only one of their eigenvalues is different from 0 and equals $n$. If the matrix $A$, on the other hand, contains some inconsistent evaluations (in practice it is often so), the weights vector can be calculated by the equation $\left(A-\lambda_{\max } I\right) w=0$ where $\lambda_{\max }$ is the biggest eigenvalue of matrix $A$. The weights are normalized by constraint $\sum w_{i}=1$. Due to this matrix features the $\lambda_{\max } \geq n$ is valid, whereas the difference $\lambda_{\max }-n$ is used for measuring the assessment consistency. By means of consistency indices $C I=\left(\lambda_{\max }-n\right) /(n-1)$ it is possible calculate the consistency ratio $C R=C 1 / R I$, where $R I$ is the random index (consistency index for matrices with random generated pairwise comparisons. The table 1 with the $R I$ values computed by simulation is used for calculation of the $C R$ ratio.

\begin{tabular}{|c|c|c|c|c|c|c|c|c|c|c|}
\hline $\boldsymbol{n}$ & 1 & 2 & 3 & 4 & 5 & 6 & 7 & 8 & 9 & 10 \\
\hline $\boldsymbol{R I}$ & 0 & 0 & 0,52 & 0,89 & 1,11 & 1,25 & 1,35 & 1,40 & 1,45 & 1,49 \\
\hline
\end{tabular}

Table 1: RI values 
If $C R \leq 0,10$ is valid for matrix $A$, the evaluations of relative importance of criteria (alternatives priorities) can be considered acceptable. If this is not the case, reasons for the unacceptably high evaluation inconsistency should be detected.

The bank rating model presented in this paper is set upon the AHP method. There are several reasons why this method has been chosen, such as containing the quality and quantity criteria, all the criteria not playing an equal role, and, last but not least, having a quality software Expert Choice (Expert Choice, Inc. 1995), to support the development of the model and also to make possible the detailed analysis of sensitivity of the end ranking list to the changes in values which are subject to individual assessment.

\section{The AHP model for bank comparing and rating}

The tables 2 and 3 shows the structure of criteria used in the bank rating model. The criteria are divided into two groups, which encompass both the quantitative indicators of bank performances and the qualitative features. The standard financial ratios are used as quantitative criteria to indicate special forms of bank performances. For the purpose of the financial ratios selection used as the quantitative criteria, the model uses the experience of the author of the article (Yeh, Q-J., 1996). This paper shows that financial ratio values can be linked with the different levels of the bank efficiencies which have been identified by means of DEA on the one hand, while on the other hand, the substantial degree of interconnection between the bank business strategy and the observed financial ratio values has been found. Due to their numerousness they have been sub-grouped into: liquidity, efficiency, profitability and capital adequacy. These terms indicate the bank performances that are measured by sub-criteria within a particular group. In our model the similar set of bank performance indicators are used.

The activity of comparing and bank rating takes into account certain features which do not dispose with the developed quantitative metrics. The model includes the possibility to assess the quality of bank management, the quality of shareholders' support, the significance and the role of the bank in the financial system of the country and the time-related establishment of the bank. All of these features are listed in the table 3 . It also provides a brief description of their role in the model.

In a case when a rating list covering a larger number of banks is to be made, a consistent application of the basic AHP model requiring the assessment of the relative significance for the pairs on all the subcriteria of the lowest criteria structure level would diminish its applicability - the number of necessary comparisons in the pairs would be too big. For this reason, the system utilizes the possibility (also supported by the program Expert Choice) for the spreadsheet model to be designed on the basis of defined criteria structure which then enables an individual bank's criteria-based evaluation to be synthesized into the overall score, determining the bank's position on the rating list. In order for this to be achieved, the following needed to be done: (i) define the main criteria and sub-criteria weights, by means of the basic AHP model, (ii) define the intensities for particular bank performances assessment for each of the lowest level criteria in the hierarchy structure.

The first part was completed using the standard method which takes into account the assessments of relative significance of the main criteria and sub-criteria in pairs, then with the aid of Expert Choice, their weights (ponders) were calculated. The table 6 shows the overall structure of criteria and sub-criteria with the associated weights.

The intensities for criterion bank evaluation have been defined in the following way:

\subsection{Quantity - related criteria}

Each of the indicators - financial ratios, has been divided into five degrees of intensity, which, yet again, have been deduced on the basis of the interval within which their values have been distributed. The table 4 shows the values of indicators for all banks, while the table 5 presents the relative intervals for particular degrees used for bank evaluation. 


\begin{tabular}{||c|l|}
\hline \multicolumn{1}{|c|}{ Subcriteria } & \multicolumn{1}{c|}{ Definition } \\
\hline \multicolumn{1}{|c|}{} & \multicolumn{1}{c|}{ LIQUIDITY } \\
\hline$L_{1}$ & $\begin{array}{l}\text { Cash and cash equvivalent +cash due from financial } \\
\text { institutions / total deposits }\end{array}$ \\
\hline$L_{2}$ & Total loans / total deposits \\
\hline$L_{3}$ & Net cash flow from operating activities / total cash flow \\
\hline \multicolumn{2}{|c|}{ EFFIENCY } \\
\hline$E_{1}$ & Operating cost / operating income \\
\hline$E_{2}$ & Loan loss reserves / gross loans \\
\hline$E_{3}$ & Provisions for loans / net interest income \\
\hline$E_{4}$ & Operating income / total number of employees \\
\hline \multicolumn{2}{|c|}{ PROFITABILITY } \\
\hline$P_{1}$ & Profit before taxes / equity \\
\hline$P_{2}$ & Profit before taxes / asset \\
\hline$P_{3}$ & Profit before taxes / operating income \\
\hline \multicolumn{2}{|c|}{ CAPITAL ADEQUACY } \\
\hline$C_{1}$ & Total liabilities / equity \\
\hline$C_{2}$ & Equity / loans \\
\hline$C_{3}$ & Total deposits / equity \\
\hline$C_{4}$ & Capital adequacy ratio \\
\hline \hline
\end{tabular}

Table 2: Financial criteria and subcriteria

The graphic presentation of the principle for this interval determination is shown in the next figure :

\begin{tabular}{|c|c|c|c|c|c|}
\hline \multirow{2}{*}{$\begin{array}{l}\text { the worst value } \\
\quad 15 \%\end{array}$} & \multicolumn{4}{|c|}{ mean value } & the best valu \\
\hline & $20 \%$ & $15 \%$ & $15 \%$ & $20 \%$ & $15 \%$ \\
\hline$B E D(1)$ & $\operatorname{ATISFIED(2)}$ & & & $V E R Y G(4)$ & EXCELLENT(5) \\
\hline
\end{tabular}

Figure 2: Interval limits determining

\subsection{Quality - related criteria}

The type of assessment used in CAMEL system combined with another system used in one foreign bank whose original purpose was to help make decisions on buying shares in banks, served as a pattern for assessment of the quality features intensity, are actually used as qualitative criteria in our model. The table 3 specifies the indications referring to the recognition of the intensity of certain gradations in the features that are exploited in the assessment.

It has earlier been stated that the CAMEL system disposes with five grades per criterion. The authors of this paper were enabled to have insight into the system used by a foreign investor (therefore, it is their best interest for a detailed presentation or citation of the origin not to be given here), which consequently applies four degrees of intensity for each quality criterion. The possibility of producing a distinct quality evaluation depends furthermost on the availability and quality of information. Since the banks are obliged to provide the bank supervision agencies with all the required data, they are positioned favourably enough to be able to recognise the finer graduations in quality criteria. In order to rate the Croatian banks through the described model, it was possible to carry out the assessment exploiting the data and information available to the public by means of specialist literature and other media. Neither the quality of the information contents or the quantity of the data, however, lead to a greater precision in quality assessment. That is why only three-level (degree) scales are employed in the quality criteria within the model. The table 3 describes also the degrees of intensity for quality criteria. 


\begin{tabular}{|c|c|c|}
\hline \multicolumn{2}{|c|}{ Intensities } & Definition \\
\hline \multicolumn{3}{|r|}{ SUPPORT } \\
\hline 1 & Unstable & Shareholders support is unstable. \\
\hline 2 & Expected & Shareholders support can be expected. \\
\hline 3 & No doubt & No doubt that shareholders support will be given. \\
\hline \multicolumn{3}{|r|}{ SIGNIFICANCE } \\
\hline 1 & Small & The bank has no determining market share in the banking system. \\
\hline 2 & Medium & $\begin{array}{l}\text { The bank has a considerable market share as to its size, or covers the } \\
\text { requirements of a significant special market segment. }\end{array}$ \\
\hline 3 & High & $\begin{array}{l}\text { The bank has a considerable market share and its activity has an } \\
\text { influence on the operation of the banking system. }\end{array}$ \\
\hline \multicolumn{3}{|r|}{ MANAGEMENT } \\
\hline 1 & Low & $\begin{array}{l}\text { The members of the management often fluctuate, the problem } \\
\text { solving capacity is missing. }\end{array}$ \\
\hline 2 & Medium & $\begin{array}{l}\text { There are no significant personal changes in the management; there } \\
\text { is en adequate administration, problems occur very rarely. }\end{array}$ \\
\hline 3 & High & $\begin{array}{l}\text { There are no personal changes in the management; there is en } \\
\text { adequate administration, no irregularities occur. Problems are } \\
\text { quickly and successfully solved. }\end{array}$ \\
\hline \multicolumn{3}{|r|}{ AGE (MATURITY) } \\
\hline 1 & $<5$ & Young bank institution. \\
\hline 2 & $5-10$ & Not $(\mathrm{Y}$ or $\mathrm{M})$ \\
\hline 3 & $>10$ & Matured bank institution. \\
\hline
\end{tabular}

Table 3 : Criteria and intensities for quality rating

\section{The model implementation}

The feasibility of the model implementation was tested on a number of Croatian banks accounting for $90 \%$ of the total banking assets. The data of their activities (data reflecting the year 1999) were sourced from the annual business reports. Financial ratio values serving as quantity criteria are to be found in the table 4. Table 5, however, contains the marginal values of quantity criteria, which, for their part, break the different grades (intensities) that fill the ratings model, developed with the aid of DSS Expert Choice. These values were calculated on the principle elaborated in the figure 2. The bank grades based on the quality criteria are given in the table 6 . The end rating list of banks is surveyed in the table 6 .

\section{Conclusion}

Banks can compare for different reasons. The criteria exploited vary in their significance but they range from quantity to quality criteria. The problem of the complexity of bank performance evaluation makes the development and the application of standard models more difficult, while at the same time actually presents a motivation for the development of new, more flexible models, which, again, can be adapted to specific interest positions of those who compare the banks. The paper shows that AHP method is very appropriate for the development of such models. It is of special interest that this method not only provides the development of the multi-criteria evaluation models but also makes the comparison of a small number of banks possible, the feature that places it ahead of different variations of DEA method. In view of the fact that expert evaluations are to be included in the bank evaluation process, the possibility to measure the consistency of subjective assessments presents an outstanding merit of the AHP method. Debates with banking experts revealed that the possibility of sensitivity analysis aided by the program Expert Choice forms an extra argument in favour of the applicability of the AHP- method- based model. Future research should be directed towards the model specialisation for specific purposes, such as assessment of feasibility of equity buying, banks deposits security assessment, comparison of banks with similar business orientation etc. 


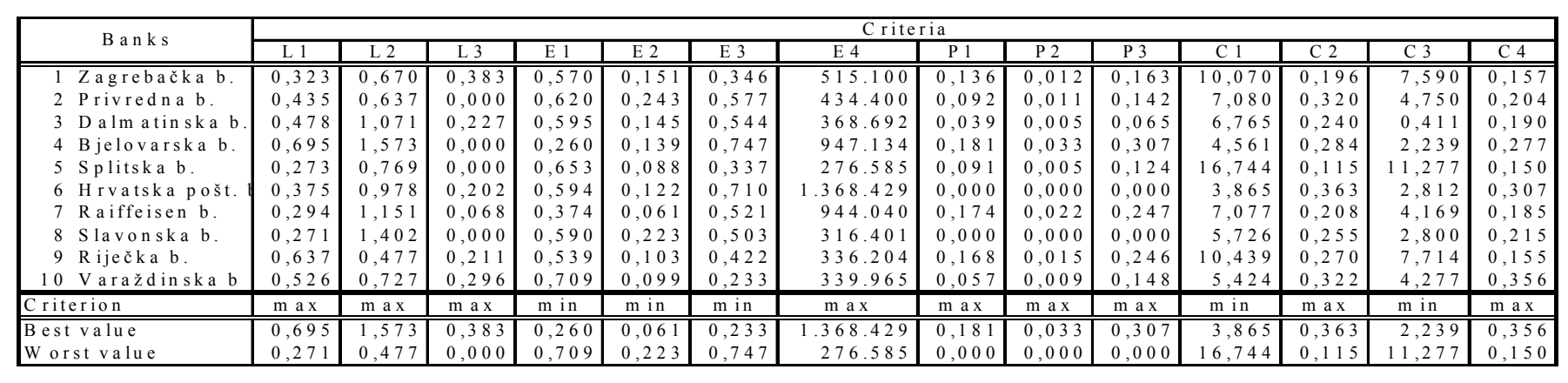

Table 4: Financial ratio values

\begin{tabular}{|l|c|c|c|c|c|c|c|c|c|c|c|c|c|c|}
\hline Criterion & L1 & L2 & L3 & E1 & E2 & E3 & E4 & P1 & P2 & P3 & C1 & C2 & C3 & C4 \\
\hline \hline Typ & $\max$ & $\max$ & $\max$ & $\min$ & $\min$ & $\min$ & $\max$ & $\max$ & $\max$ & $\max$ & $\min$ & $\max$ & $\min$ & $\max$ \\
\hline \hline Bed & 0,334 & 0,642 & 0,057 & 0,641 & 0,216 & 0,670 & 440.362 & 0,027 & 0,005 & 0,046 & 14,812 & 0,153 & 9,921 & 0,181 \\
Satisfied & 0,419 & 0,861 & 0,134 & 0,552 & 0,180 & 0,567 & 658.730 & 0,063 & 0,011 & 0,107 & 12,236 & 0,202 & 8,114 & 0,222 \\
Good & 0,547 & 1,189 & 0,249 & 0,417 & 0,125 & 0,413 & 986.284 & 0,118 & 0,021 & 0,200 & 8,372 & 0,277 & 5,402 & 0,284 \\
Very good & 0,632 & 1,408 & 0,326 & 0,327 & 0,089 & 0,310 & 1.204 .652 & 0,154 & 0,028 & 0,261 & 5,797 & 0,326 & 3,595 & 0,325 \\
Excellent & 0,695 & 1,573 & 0,383 & 0,260 & 0,061 & 0,233 & 1.368 .429 & 0,181 & 0,033 & 0,307 & 3,865 & 0,363 & 2,239 & 0,356 \\
\hline
\end{tabular}

Table 5: Interval limits of financial ratios values determining equivalent qualitative grades

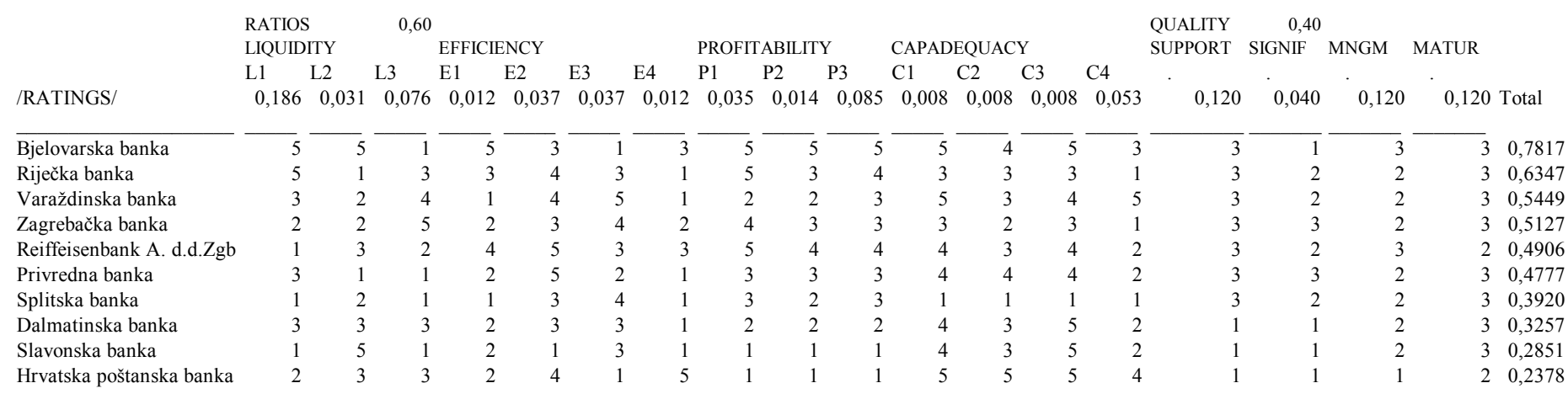

Table 6: Bank rating and final scor spreadsheet 


\section{References}

Babić, Z., Belak, V. and Tomić-Plazibat, N. (1999), "Ranking of croatian banks according to business efficiency", Proceedings of the $5^{\text {th }}$ International Symposium on Operational Research, Preddvor, Slovenia.

Belak, V., Kolaković, M. (1998), "Organizational efficiency and reingineering of croatian banks" (in croatian), Slobodno poduzetništvo, 3, 3-17.

Brockett, P.L., Charnes, A., Cooper, W.W., Hwang, Z.M. and Sun, D.B. (1997), "Data transformations in DEA cone ratio envelopment approaches for monitoring bank performances", European Journal of Operational Research, 98, 250-268.

Brans, J.P., Mareschal, B. and Vincke, Ph. (1986), "How to select and how to rank projects: The PROMETHEE method ", European Journal of Operational Research, 24, 228-238.

Charnes A, Cooper WW and Rhodes E (1978), Measuring the efficiency of decision making units, Eur. J. of Opl. Res., 2, pp 429-444.

Cooper, W. W., Seiford, L. M., Tone K. (2000), Data envelopment analysis: a comprehensisve text with models, applications, references, and DEA-Solver software, Kluwer Academic Publishers, Norwell.

Expert Choice, Inc. (1995), Expert Choice Decision Support Software, RWS publications, Pittsburg.

Saaty, T.L. (1980), The Analytic Hierarchy Process, McGraw-Hill, New York.

Yeh, Q-J. (1996), “The Application of Data Envelopment Analysis in Conjuction with Financial Ratios for Bank Performance Evaluation", Journal of the Operational Research Society, 47, 980-988. 
